\title{
Height of Water Pool in the Roll Nip of Secondary Cooling Zone in Continuous Slab Caster: Application of Open Channel Hydraulics
}

\begin{abstract}
SOMAYEH KHANI, HEINZ PALKOWSKI, and KLAUS SCHWERDTFEGER
In continuous casting of steel, the strand is cooled in the upper part of the secondary cooling zone with water sprayed by nozzles towards the strand surface. The water accumulates in the nip of the lower roll of a roll pair, forming a water pool which then drains off towards the ends of the roll. In the present work, open channel hydraulics was applied for computation of the water pool height in the nip between roll and strand in continuous slab casting. The differential equation describing the change of pool height for the spatially varied flow with increasing discharge was solved with the Runge-Kutta technique using as boundary condition the pool height at the end of the nip. The effects of the Manning friction factor $n$ and the energy coefficient $\alpha$ were determined in sets of computation. It was shown that the hydraulic theory could predict water profiles in the nip of continuous casting rolls to a good approximation.
\end{abstract}

https://doi.org/10.1007/s11663-021-02294-4

(C) The Author(s) 2021

\section{INTRODUCTION}

BELOW the mold in the so-called secondary cooling zone, usually, the slab is sprayed with water emerging from nozzles arranged in the spaces between the rolls. The heat transfer is complex involving several mechanisms. Figure 1 shows a roll pair with the different cooling zones which are, in addition to the zone of direct impingement, the zones of the downwards flowing water, of the water pool above the lower roll, of contact between roll and strand, and of dry cooling.

This paper deals with the zone of water pool above the rolls. The region is also called water accumulation zone or nip zone. Cooling of the strand surface occurs, due to high temperature, by stable film boiling. That is, a coherent water vapor film separates the hot strand surface from the water pool. There are many heat flux density-temperature and heat transfer coefficient-temperature diagrams for boiling of water at a hot plate in the chemical engineering literature. For instance, in References 2 and 3, heat transfer coefficients around $1000 \mathrm{~W} \mathrm{~m} \mathrm{~m}^{-2} \mathrm{~K}^{-1}$ are given. For continuous casting conditions, the heat transfer coefficient in the pool zone

SOMAYEH KHANI; HEINZ PALKOWSKI and KLAUS SCHWERDTFEGER are with the Institut für Metallurgie, Technische Universität Clausthal, Robert Koch Straße 42, 38678 Clausthal-Zellerfeld, Germany. Contact e-mail: schwerdtf@t-online.de Manuscript submitted October 11, 2020; accepted July 30, 2021.

Article published online October 25, 2021. has been deduced as about $900 \mathrm{~W} \mathrm{~m}^{-2} \mathrm{~K}^{-1}$ from surface temperature measurements with a traveling thermocouple. ${ }^{[4]}$

For computation of the heat withdrawn in the pool (nip) zone the height of the water pool must be known. Measurements on a live caster are very difficult. But laboratory investigations are well possible. Recently, extended laboratory measurements on water pool height in the nip have been carried out. ${ }^{[5]}$ The data were analyzed using dimensional analysis. In the present work, it is investigated to which extend hydraulic theory can predict the water pool height profiles in the continuous casting nip.

Previously, spray water flow in secondary cooling of continuous casting machines has been analyzed theoretically with a particle-based numerical method. ${ }^{[6]}$ Experimental data on real casting machines are not known to the authors of this paper. But many publications and data are available on strand cooling in the secondary cooling zone.

Strand cooling in the secondary cooling is complex. In addition to the water pool there are the zones of direct spray impingement, of the downwards flowing water, of roll contact and of dry cooling, see Figure 1. Measurements of heat withdrawal by single spray nozzles have been carried out, for instance, in References 7 through 9 and were analyzed in References 10 through 12, the zone of roll contact in Reference 13 and the zone of dry cooling in Reference 12. Equations for average heat transfer coefficient were given in References 1, 4, and 14 


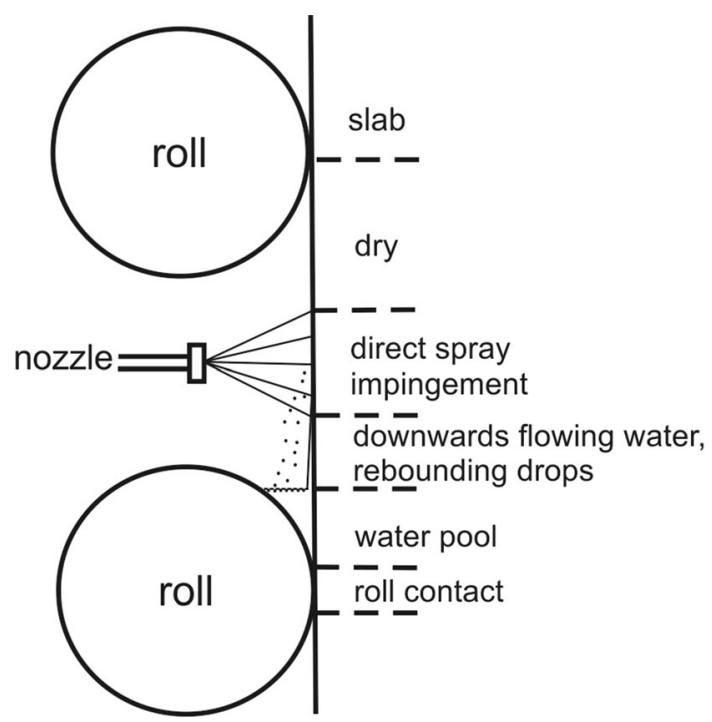

Fig. 1-Regions with different heat transfer mechanism between a roll pair in the spray zone of a slab caster. Schematical, adapted from Ref. [1].

\section{EXPERIMENTAL INVESTIGATION}

In the laboratory experiments, which were carried out in a previous investigation, ${ }^{[5]}$ the buildup of the water pool at a vertical strand surface has been measured. A photograph of the apparatus during an experiment and a perspective sketch for explanation are shown in Figure 2. The apparatus consisted of a stainless steel tube of $1000 \mathrm{~mm}$ length and 300 or $150 \mathrm{~mm}$ diameter, placed horizontally against a vertical Plexiglas (acrylic glass) plate. The tube simulates the roll in continuous casting and the plate the strand surface. Thus, the 'nip' channel is formed between tube and plate. The plate is provided with transparent millimeter paper. So, the height of the water can be seen through the $\mathrm{mm}$ paper. The water input is from a dispenser, about $1000 \mathrm{~m}$ long, made from a stainless steel pipe which has little bores at constant distances. Another wall (vertical to the 'strand plate'), called 'side-wall', closes the nip channel at one of its ends so that the water always flows to the open end of the nip. The third wall, called 'back-wall', is placed parallel to the strand plate on top of the tube for guiding the water along the tube thus avoiding uncontrolled spill-over at the back side of the tube when the flow rate was set too high. The dimensions of the laboratory setup (diameter and length of stainless steel tube) and the used water flow rate are in the range of roll dimensions and of water flow rate used in real continuous casting. The side-wall can be shifted along the tube so that also shorter lengths $(500$ and $330 \mathrm{~mm}$ ) than $1000 \mathrm{~mm}$ could be used. These lengths are denoted as $L$. They represent the half-length of the roll in the continuous casting machine, e.g. tube length $L=500 \mathrm{~mm}$ simulates a 1000 $\mathrm{mm}$ long continuous casting roll. Water flow rates were measured with the LCD-DIGITAL instrument made by
Blurea and 'manually' by collecting the off-flowing water at the end of the channel in a bucket of known volume and measuring the time for filling it. For details of the experimental technique, see the preceding paper. ${ }^{5]}$ It should be mentioned that the laboratory setup differs from the real continuous casting machine concerning the fixed tube/roll and plate/strand, which rotate or move, of course, in real continuous casting. However, the longitudinal water velocity in the nip is much higher, except in a short region close to the side-wall, than roll and strand velocity. It is assumed, therefore, that this difference does not handicap the applicability of the present data to real continuous casting.

\section{HYDRAULICS OF FLOW IN OPEN CHANNELS}

\section{A. Differential Momentum Balance}

A computation of the pool height profile can be carried out by application of the theory for the hydraulics of open-channel flow. ${ }^{[15]}$ Figure 3 illustrates the schematic of the open channel created between strand and the roll in a continuous casting process. There are two specific features of the flow in the nip between strand and roll; one is the addition of water which is continuous in length direction causing increasing discharge, and the other is the unusual cross-section of the flow, see Figure 3(b).

The governing starting differential equation for this spatially varied flow with increasing discharge is written as follows ${ }^{[15]}$ :

$$
\frac{\mathrm{d} H_{\text {pool }}}{\mathrm{d} y}=-\frac{S_{\mathrm{f}}+\frac{2 \alpha Q q}{g A^{2}}}{1-\frac{\alpha Q^{2}}{g A^{2} D_{\text {depth }}}}
$$

where $H_{\text {pool }}$ is the pool height, $y$ the spatial coordinate along the nip, $A$ the cross-sectional area of the flow, $g$ the gravity constant, $D_{\text {depth }}$ the hydraulic depth of the pool, $Q$ the discharge (volume flow rate), $q=\mathrm{d} Q / \mathrm{d} y$ the change of discharge along the nip, $S_{\mathrm{f}}$ the friction slope and $\alpha$ a coefficient for considering the non-uniform velocity distribution in the channel section. The hydraulic depth is defined as the ratio between flow area $A$ and width of the flow surface $T$ with $D_{\text {depth }}=$ $A / T$. Since the latter is equal to the increase of area $\mathrm{d} A$ with increase of pool height $\mathrm{d} H_{\text {pool }}$ and $T=\mathrm{d} A /$ $\mathrm{d} H_{\text {pool }}$, it follows

$$
D_{\text {depth }}=A \frac{\mathrm{d} H_{\text {pool }}}{\mathrm{d} A}
$$

In the continuous casting systems and in the experiments carried out by the authors ${ }^{[5]}$ the water addition is intended to be uniform, that is

$$
Q=q y
$$




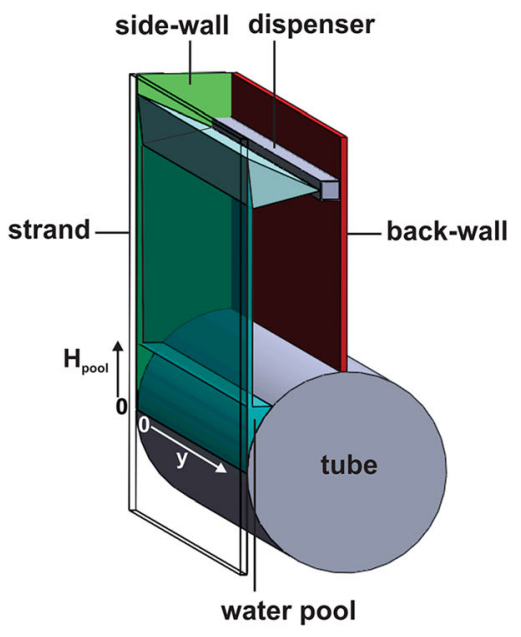

(a)

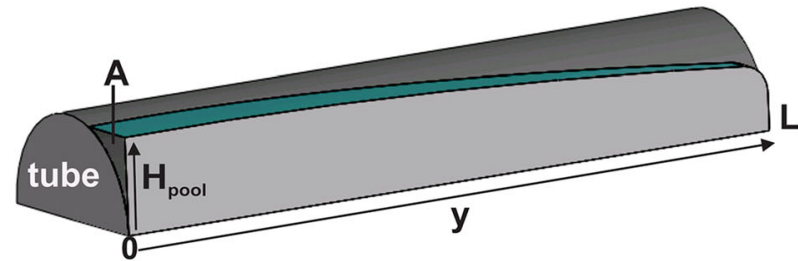

(b)

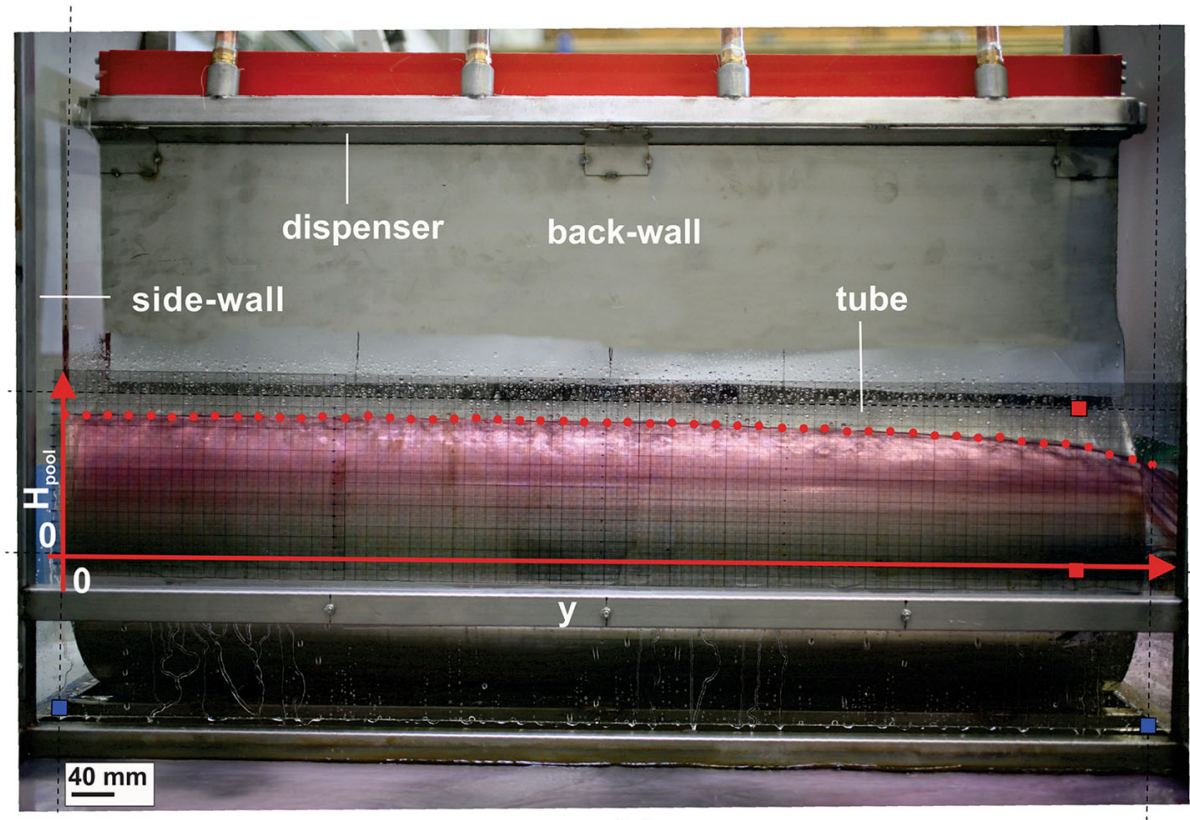

(c)

Fig. 2-Experimental setup. (a) The perspective view represents the view towards the side-wall from a vertical section at $y$. (b) Perspective view of the whole water pool. $(c)$ Photo of setup with pool profile (line of red dots) during an experiment. The water flows from left to right. The red zero-line for the pool height is the contact line between tube and strand plate. Channel length $L=1 \mathrm{~m}, R_{\mathrm{r}}=0.150 \mathrm{~m}, Q_{\mathrm{L}}=0.78 \mathrm{~L} \mathrm{~s}{ }^{-1}$. (a) and (c) from Ref. [5], reprinted by permission of the publisher (Taylor \& Francis Ltd, www.tandfonline.com).

with $q$ being constant. Inserting Eqs. [2] and [3] in [1] yields

$$
\frac{\mathrm{d} H_{\mathrm{pool}}}{\mathrm{d} y}=-\frac{S_{\mathrm{f}}+\frac{2 \alpha q^{2} y}{g A^{2}}}{1-\frac{\alpha q^{2} y^{2}}{g A^{3}}\left(\frac{\mathrm{d} A}{\mathrm{~d} H_{\mathrm{pool}}}\right)}
$$

The friction slope $S_{\mathrm{f}}$ is usually taken in open channel hydraulics in the form of the Manning formula, ${ }^{[16,17]}$ and this will be done in this paper, too:

$$
S_{\mathrm{f}}=\frac{q^{2} y^{2} n^{2}}{A^{2} R_{\mathrm{h}}^{\frac{4}{3}}}
$$

with $R_{\mathrm{h}}$ being the hydraulic radius of the flow given by the ratio of the water area $A$ and the wetted perimeter $p_{\mathrm{w}}$

$$
R_{\mathrm{h}}=\frac{A}{p_{\mathrm{w}}}
$$

and $n$ being the Manning roughness coefficient. 


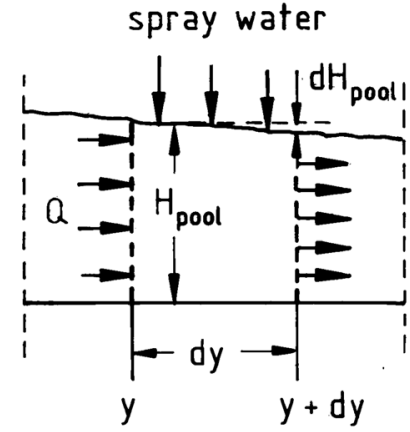

(a)

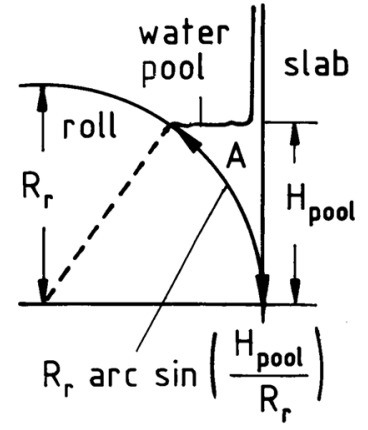

(b)
Fig. 3-Schematic diagram for explanation of force balance used in the pool height model. (a) Water profile above roll. Longitudinal section at the surface of the strand. (b) Transverse section.

\section{B. Geometry of Nip}

The formulae for $A$ and $\mathrm{p}_{\mathrm{w}}$ can be obtained by integrations of the circle equation (see Figure 3(b)). It is convenient for the later use to express these formulae in non-dimensional form. Doing so, Eqs. [7] and [8] are obtained

$$
\frac{A}{R_{\mathrm{r}}{ }^{2}}=\left[\frac{H_{\text {pool }}}{R_{\mathrm{r}}}-\frac{1}{2}\left(\frac{H_{\text {pool }}}{R_{\mathrm{r}}}\right) \sqrt{1-\left(\frac{H_{\text {pool }}}{R_{\mathrm{r}}}\right)^{2}}-\frac{1}{2} \arcsin \left(\frac{H_{\text {pool }}}{R_{\mathrm{r}}}\right)\right]
$$

and

$$
\frac{p_{\mathrm{w}}}{R_{\mathrm{r}}}=\left[\frac{H_{\text {pool }}}{R_{\mathrm{r}}}+\arcsin \left(\frac{H_{\text {pool }}}{R_{\mathrm{r}}}\right)\right]
$$

in which $R_{\mathrm{r}}$ is the roll radius, $R_{\mathrm{r}}=D_{\mathrm{r}} / 2$.

\section{Use of Froude Criterion as Boundary Condition at the End of the Channel}

The integration of Eq. [4] requires a boundary condition. Often, in open channel flow, the condition of free overfall is used at the end of the channel, ${ }^{[15]}$ that is the Froude number $F r$ is set to one, $F r=1$. The term 'free overfall' is applied in open channel hydraulics for the sudden drop of the water surface at the end of the channel.

The Froude number for flow along an open channel is given as

$$
F r=\frac{v}{\sqrt{g D_{\text {depth }}}}
$$

where $v$ is the velocity obtained as

$$
v=\frac{Q}{A}
$$

Replacing $D_{\text {depth }}$ in Eq. [9] by [2] and the velocity $v$ in [9] by [10] yields, after some manipulation

$$
\frac{g R_{\mathrm{r}}{ }^{5}}{Q^{2}}=\frac{R_{\mathrm{r}}{ }^{5} \mathrm{~d} A}{A^{3} \mathrm{~d} H_{\text {pool }}}\left(\frac{1}{F r^{2}}\right)
$$

Using Eq. [11] at the end of the channel, $y=L$, the discharge $Q$ is set to $Q_{\mathrm{L}}$ and the Froude number $F r$ to 1 , yielding

$$
\frac{g R_{\mathrm{r}}^{5}}{Q_{\mathrm{L}}{ }^{2}}=R_{\mathrm{r}}^{5}\left(\frac{\mathrm{d} A}{A^{3} \mathrm{~d} H_{\text {pool }}}\right)_{y=L}
$$

The quantity $\left(\frac{\mathrm{d} A}{A^{3} \mathrm{~d} H_{\mathrm{pool}}}\right)_{y=L}$ is obtained from Eq. [7] and inserted into Eq. [12] yielding

$$
\frac{g R_{\mathrm{r}}{ }^{5}}{Q_{\mathrm{L}}{ }^{2}}=\frac{1-\sqrt{1-\left(H_{\text {pool }, \mathrm{L}} / R_{\mathrm{r}}\right)^{2}}}{\left(\frac{H_{\text {pool, } \mathrm{L}}}{R_{\mathrm{r}}}-\frac{H_{\text {pool, } \mathrm{L}}}{2 R_{\mathrm{r}}} \sqrt{1-\left(H_{\mathrm{pool}, \mathrm{L}} / R_{\mathrm{r}}\right)^{2}}-\frac{1}{2} \arcsin \left(H_{\mathrm{pool}, \mathrm{L}} / R_{\mathrm{r}}\right)\right)^{3}}
$$

The required boundary condition is obtained by solution of Eq. [13]. Table I gives the development of the $\left(H_{\text {pool, } \mathrm{L}} / R_{\mathrm{r}}\right)$ values used in the computation of the $\mathrm{H}_{\text {pool }}$ profiles presented in Section IV of this paper.

\section{Significance of $\alpha$}

The quantity $\alpha$ in Eq. [4] is denoted as energy coefficient ${ }^{[15]}$ and is intended to consider the non-uniform velocity distribution in the channel section. It is to be noted that $\alpha$ should be smaller than 1 . This can be shown as follows:

For the end of the channel, $y=L$, Eq. [4] is written as

$$
\left(\frac{\mathrm{d} H_{\text {pool }}}{\mathrm{d} y}\right)_{\mathrm{L}}=\frac{-S_{\mathrm{f}}-\frac{2 \alpha Q_{\mathrm{L}}{ }^{2}}{L g A_{\mathrm{L}}{ }^{2}}}{1-\frac{\alpha Q_{\mathrm{L}}^{2}}{g}\left(\frac{\mathrm{d} A}{A^{3} \mathrm{~d} H_{\text {pool }}}\right)_{\mathrm{L}}}
$$

Using Eqs. [12] in [14] yields

$$
\left(\frac{\mathrm{d} H_{\text {pool }}}{\mathrm{d} y}\right)_{\mathrm{L}}=\frac{-S_{\mathrm{f}}-\frac{2 \alpha Q_{\mathrm{L}}^{2}}{\operatorname{Lg} A_{\mathrm{L}}^{2}}}{1-\alpha}
$$

The numerator of Eq. [15] is negative. The denominator is zero for $\alpha=1$ and hence $\left(\frac{\mathrm{d} H_{\text {pool }}}{\mathrm{d} y}\right)_{\mathrm{L}}=\infty$ which makes difficulties for the numerical integration. In case of $\alpha<1$ the denominator is positive and $\left(\frac{\mathrm{d} H_{\text {pool }}}{\mathrm{d} y}\right)_{\mathrm{L}}$ would be negative and finite as required. For $\alpha>1$ value of $\left(\frac{\mathrm{d} H_{\text {pool }}}{\mathrm{d} y}\right)_{\mathrm{L}}$ would be positive which is wrong. Therefore, $\alpha$ $>1$ cannot be chosen for the computation in this study.

\section{E. Final Differential Equation and Integration Method}

Using Eqs. [5] through [8] in [4] yields Eq. [16] which is the final differential equation to be integrated. As can be seen, $d \mathrm{H}_{\text {pool }} / d \mathrm{y}$ is a function of height $H_{\text {pool }}$ as well as length coordinate $y$ of the roll in the form of an ordinary first order differential equation. The Runge-Kutta method (RKM) is used for integrating this equation. For starting the integration, an initial value of $H_{\text {pool }}$ is required. Since in the current study, $H_{\text {pool, } 0}$ at $y=0$ as an initial condition for RKM is unknown, the value of $H_{\text {pool, } \mathrm{L}}$ at $y=L$ (computed with Froude criterion using Eq. [13]) was taken as a beginning point. Therefore, the backward integration was implemented from a known 
Table I. $H_{\text {pool,L }}$ Values According to Froude Criterion as Computed With Eq. [13].

\begin{tabular}{|c|c|c|c|c|c|}
\hline$L(\mathrm{~mm})$ & $R_{\mathrm{r}}(\mathrm{mm})$ & $Q_{\mathrm{L}}\left(\mathrm{L} \mathrm{s}^{-1}\right)$ & $g R_{\mathrm{r}}^{5} / Q_{\mathrm{L}}{ }^{2}$ & $H_{\mathrm{L}} / R_{\mathrm{r}}$ & $H_{\mathrm{L}}(\mathrm{mm})$ \\
\hline 1000 & 150 & 1.54 & 314.006 & 0.83966 & 125.95 \\
\hline 1000 & 150 & 0.775 & 1239.869 & 0.69516 & 104.27 \\
\hline 1000 & 150 & 0.39 & 4896.097 & 0.57418 & 86.13 \\
\hline 500 & 150 & 0.72 & 1436.528 & 0.68113 & 102.17 \\
\hline 500 & 150 & 0.4 & 4654.352 & 0.57826 & 86.74 \\
\hline 500 & 150 & 0.19 & 20628.706 & 0.46914 & 70.37 \\
\hline 330 & 150 & 0.545 & 2507.184 & 0.63041 & 94.56 \\
\hline 330 & 150 & 0.27 & 10215.313 & 0.51791 & 77.69 \\
\hline 330 & 150 & 0.13 & 44064.869 & 0.42148 & 63.22 \\
\hline 330 & 75 & 0.14 & 1187.335 & 0.69934 & 52.45 \\
\hline 330 & 75 & 0.097 & 2473.351 & 0.63160 & 47.37 \\
\hline 330 & 75 & 0.071 & 4616.496 & 0.57892 & 43.42 \\
\hline
\end{tabular}

downstream height $H_{\text {pool,L }}$. Consequently, to be able to use $H_{\text {pool,L }}$ as an initial condition in RKM, the new length variable $Y$, defined as $Y=L-y$, and $\mathrm{d} Y=-\mathrm{d} y$ were inserted in Eq. [4] for $y$ and $\mathrm{d} y$, respectively, yielding Eq. [17]. After using Eqs. [5] through [8] in [17], the final Eq. [18] results which is to be integrated starting with the value of $H_{\text {pool, } \mathrm{L}}$ at $Y=0$.

\section{F. Use of MATLAB Software}

Equation [18] as the first order differential equation, showed to be too complicated to be solved directly by ode45 solver in MATLAB software, that is, a simplification had to be carried out. For this purpose, a set of codes was written for both simplifications of the equation and solving with ode45 solver. Therefore, the MATLAB software was used to compute the series expansions of Eqs. [7] and [8] for $A / R_{\mathrm{r}}{ }^{2}$ and $p_{\mathrm{w}} / R_{\mathrm{r}}$, and these were then inserted into Eqs. [5], [6] and [4]. The series expansion forms are given as Eqs. [19] and [20].

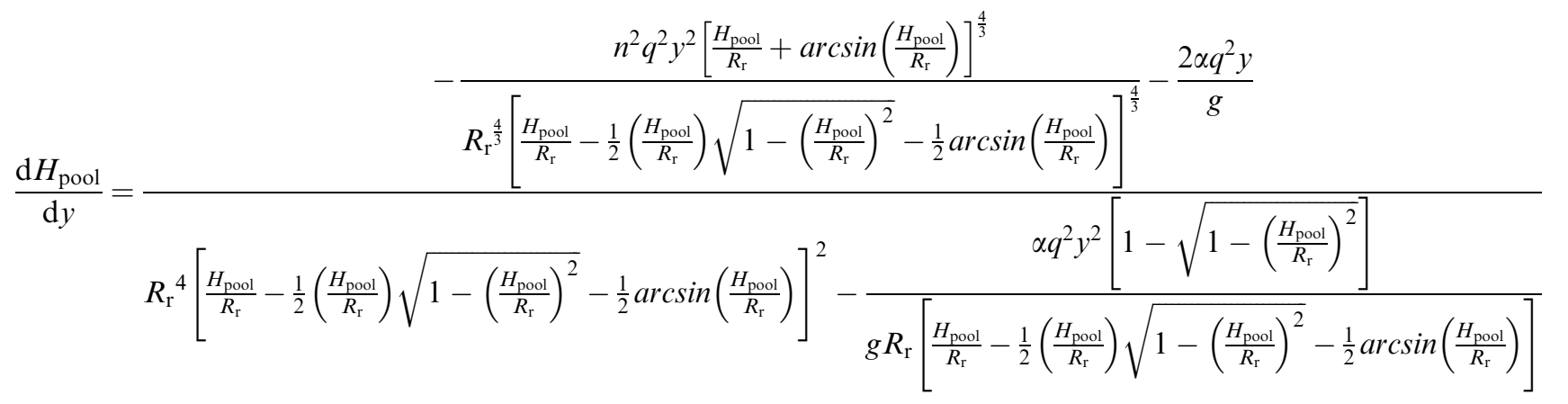

$$
\begin{aligned}
& \frac{\mathrm{d} H_{\mathrm{pool}}}{d Y}=\frac{S_{\mathrm{f}}+\frac{2 \alpha q^{2}(L-Y)}{g A^{2}}}{1-\frac{\alpha q^{2}(L-Y)^{2}}{g A^{3}}\left(\frac{\mathrm{d}_{A}}{\mathrm{~d} H_{\mathrm{pool}}}\right)}
\end{aligned}
$$

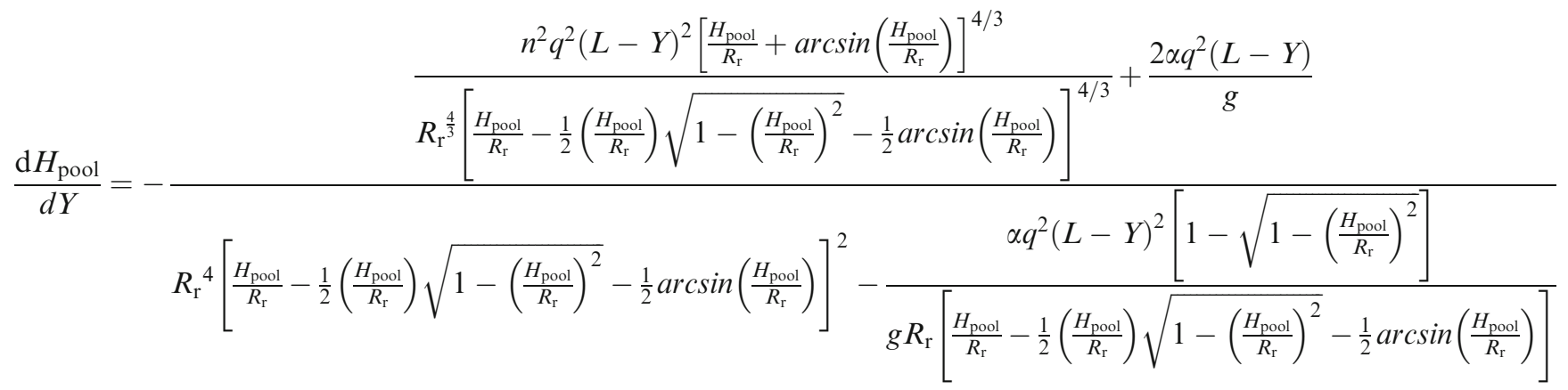




$$
\begin{aligned}
\frac{A}{R_{\mathrm{r}}{ }^{2}}= & -\frac{\pi}{4}+\frac{H_{\text {pool }}}{R_{\mathrm{r}}}+2.121\left(1-\frac{H_{\text {pool }}}{R_{\mathrm{r}}}\right)^{3 / 2} \\
& -0.141\left(1-\frac{H_{\text {pool }}}{R_{\mathrm{r}}}\right)^{5 / 2}-12.626 \times 10^{-3}\left(1-\frac{H_{\text {pool }}}{R_{\mathrm{r}}}\right)^{\frac{7}{2}} \\
& -2.455 \times 10^{-3}\left(1-\frac{H_{\text {pool }}}{R_{\mathrm{r}}}\right)^{\frac{9}{2}}-6.278 \times 10^{-4}\left(1-\frac{H_{\text {pool }}}{R_{\mathrm{r}}}\right)^{\frac{11}{2}} \\
& -1.860 \times 10^{-4}\left(1-\frac{H_{\text {pool }}}{R_{\mathrm{r}}}\right)^{\frac{13}{2}}-6.041 \times 10^{-5}\left(1-\frac{H_{\text {pool }}}{R_{\mathrm{r}}}\right)^{\frac{15}{2}} \\
& -2.094 \times 10^{-5}\left(1-\frac{H_{\text {pool }}}{R_{\mathrm{r}}}\right)^{\frac{17}{2}}-7.613 \times 10^{-6}\left(1-\frac{H_{\text {pool }}}{R_{\mathrm{r}}}\right)^{\frac{19}{2}} \\
& -2.870 \times 10^{-6}\left(1-\frac{H_{\text {pool }}}{R_{\mathrm{r}}}\right)^{\frac{21}{2}}-11.137 \times 10^{-7}\left(1-\frac{H_{\text {pool }}}{R_{\mathrm{r}}}\right)^{\frac{23}{2}} \\
& -4.424 \times 10^{-7}\left(1-\frac{H_{\text {pool }}}{R_{\mathrm{r}}}\right)^{\frac{25}{2}}-1.792 \times 10^{-7}\left(1-\frac{H_{\text {pool }}}{R_{\mathrm{r}}}\right)^{\frac{27}{2}} \\
& -7.381 \times 10^{-8}\left(1-\frac{H_{\text {pool }}}{R_{\mathrm{r}}}\right)^{29 / 2}
\end{aligned}
$$

$$
\begin{aligned}
& \frac{p_{\mathrm{w}}}{R_{\mathrm{r}}}=\frac{\pi}{2}+\frac{H_{\text {pool }}}{R_{\mathrm{r}}}-1.414\left(1-\frac{H_{\text {pool }}}{R_{\mathrm{r}}}\right)^{1 / 2}-1.174 \\
& \times 10^{-1}\left(1-\frac{H_{\mathrm{pool}}}{R_{\mathrm{r}}}\right)^{3 / 2}-2.652 \\
& \times 10^{-2}\left(1-\frac{H_{\text {pool }}}{R_{\mathrm{r}}}\right)^{5 / 2}-7.891 \\
& \times 10^{-3}\left(1-\frac{H_{\text {pool }}}{R_{\mathrm{r}}}\right)^{7 / 2}-2.685 \\
& \times 10^{-3}\left(1-\frac{H_{\text {pool }}}{R_{\mathrm{r}}}\right)^{9 / 2}-9.885 \\
& \times 10^{-4}\left(1-\frac{H_{\text {pool }}}{R_{\mathrm{r}}}\right)^{11 / 2}-3.835 \\
& \times 10^{-4}\left(1-\frac{H_{\text {pool }}}{R_{\mathrm{r}}}\right)^{13 / 2}-1.543 \\
& \times 10^{-4}\left(1-\frac{H_{\text {pool }}}{R_{\mathrm{r}}}\right)^{15 / 2}-6.382 \\
& \times 10^{-4}\left(1-\frac{H_{\text {pool }}}{R_{\mathrm{r}}}\right)^{17 / 2}-2.696 \\
& \times 10^{-5}\left(1-\frac{H_{\text {pool }}}{R_{\mathrm{r}}}\right)^{19 / 2}-1.159 \\
& \times 10^{-5}\left(1-\frac{H_{\text {pool }}}{R_{\mathrm{r}}}\right)^{21 / 2}-5.049 \\
& \times 10^{-6}\left(1-\frac{H_{\text {pool }}}{R_{\mathrm{r}}}\right)^{23 / 2}-2.226 \\
& \times 10^{-6}\left(1-\frac{H_{\text {pool }}}{R_{\mathrm{r}}}\right)^{25 / 2}-9.906 \\
& \times 10^{-7}\left(1-\frac{H_{\text {pool }}}{R_{\mathrm{r}}}\right)^{27 / 2}-4.448 \\
& \times 10^{-7}\left(1-\frac{H_{\text {pool }}}{R_{\mathrm{r}}}\right)^{29 / 2}
\end{aligned}
$$

As shown in Figures 4 and 5, the series expansions agree very nicely with the exact functions of $A / R_{\mathrm{r}}{ }^{2}$ and $p_{\mathrm{w}} / R_{\mathrm{r}}$.

MATLAB software is well known and frequently used. Nevertheless, we tested MATLAB by computing the water height profile in a rectangular channel with no friction for which the analytical solution is available. ${ }^{[14]}$ Excellent agreement came out between the two profiles.

\section{RESULTS OF COMPUTATIONS}

\section{A. Influence of $\alpha$ on Computed $H_{\text {pool,o }} / R_{r}$ Value}

As described previously, $\alpha$ determines the slope of the water height profile at $y=L$. It has been demonstrated that $\alpha$ must be less than 1 . Therefore, to investigate the effect of $\alpha$, different $\alpha$ values less than 1 were used in the computations. Since for the channels with soft steel surface the Manning factor $n$ has been reported to be around $0.012 \mathrm{~s} \mathrm{~m}^{-1 / 3},{ }^{[16]}$ computations were carried out with this $n$ value for four different $Q$ values. The bar charts in Figure 6 show that $H_{\text {pool, } 0} / R_{\mathrm{r}}$ increases somewhat with increasing $\alpha$ value. It is to be mentioned that using $Q_{\mathrm{L}}=1.54 \mathrm{~L} \mathrm{~s}^{-1}, H_{\text {pool, } 0} / R_{\mathrm{r}}$ comes out larger than 1 for $\alpha$ larger than 0.75 which, of course, is wrong. For lower $\mathrm{Q}_{\mathrm{L}}, H_{\text {pool, } 0} / R_{\mathrm{r}}$ is below 1 up to $\alpha=0.99$. We selected $\alpha=0.7$ for the computation of the following diagrams.

\section{B. Influence of Manning Friction Factor $n$ on Computed $H_{\text {pool,o }} / R_{r}$ Value}

In order to determine the influence of $\mathrm{n}$ on the water height profile, different $\mathrm{n}$ values were used in the computations. Figure 7 shows that $H_{\text {pool, } 0} / R_{\mathrm{r}}$ increases with increasing $\mathrm{n}$, as expected. Increasing $\mathrm{n}$ means

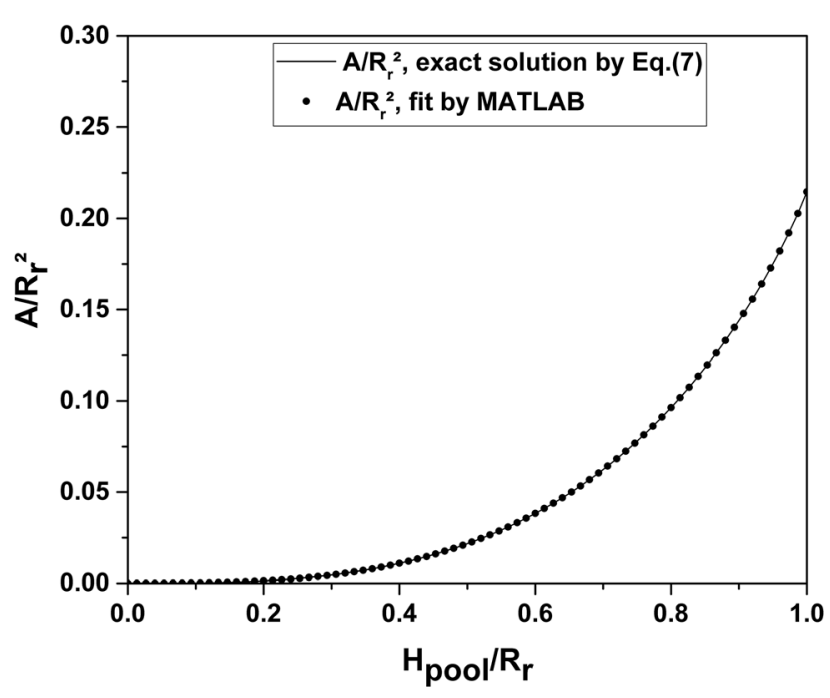

Fig. 4-Dimensionless flow area as a function of dimensionless pool height. Comparison between MATLAB fit Eq. [19] and exact Eq. [7]. 


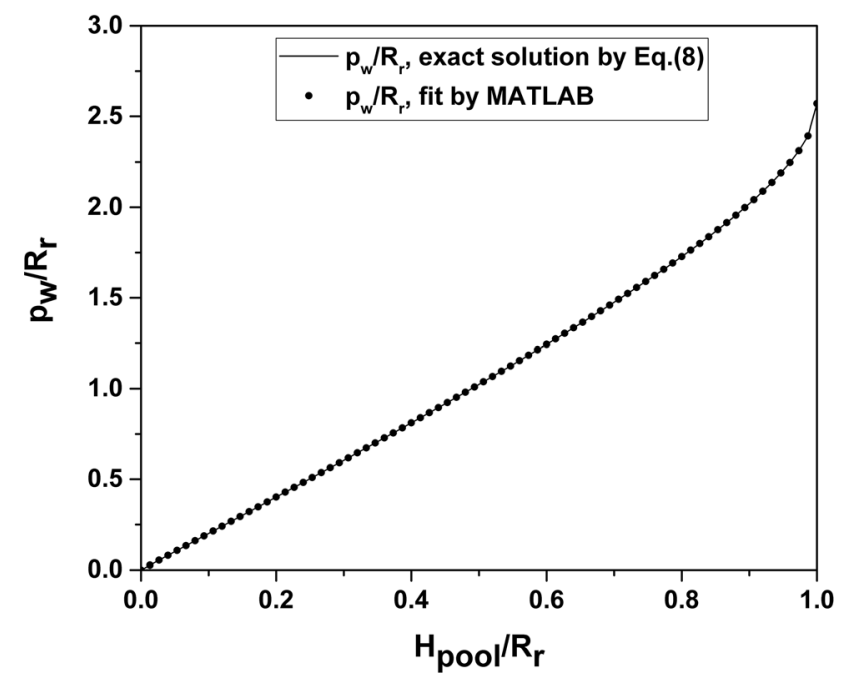

Fig. 5-Dimensionless wetted perimeter as a function of dimensionless pool height. Comparison between MATLAB fit Eq. [20] and exact Eq. [8].

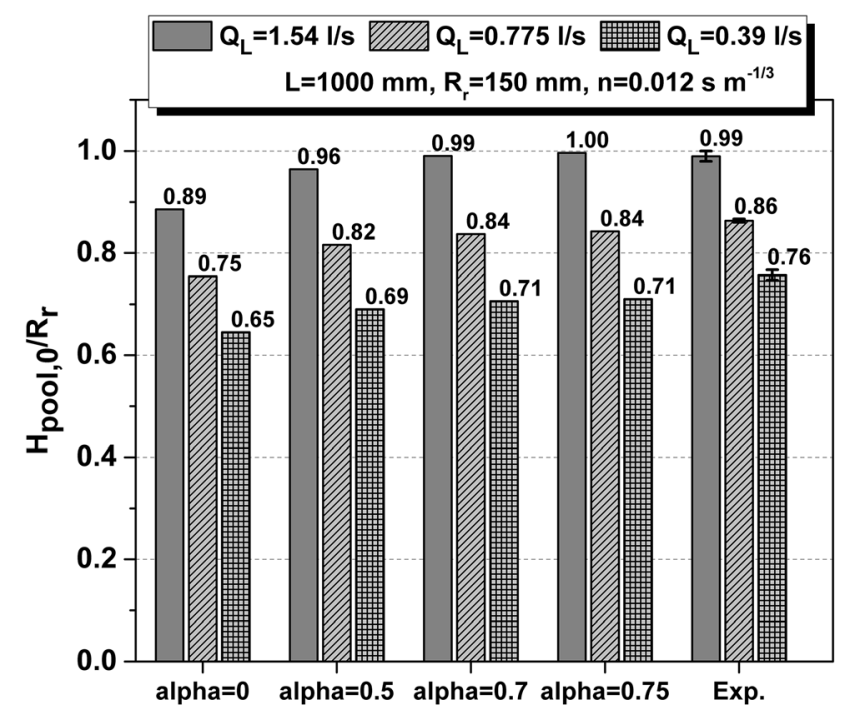

Fig. 6-Variation of the computed $H_{\text {pool, } 0}$ with changing $\alpha$ values, and comparison with experimental results.

raising the friction in the channel and this results in increasing the water head at $y=0$. But the effect of friction is small. This fact also affects the applicability of the present data to real continuous casting. In a live caster the water is boiling at the strand side and, consequently, the friction is changed. But since the effect of friction on pool height is small, pool height changes only little. Thus, the applicability of the data to real continuous casting is not narrowed.

\section{Computed Height Profiles}

Figure 8 presents a comparison between computed water height profiles and experimentally measured profiles. For $\alpha$ and $n$ the values 0.7 and $0.012 \mathrm{~s} \mathrm{~m}^{-1 / 3}$ were chosen, respectively. As can be seen, both

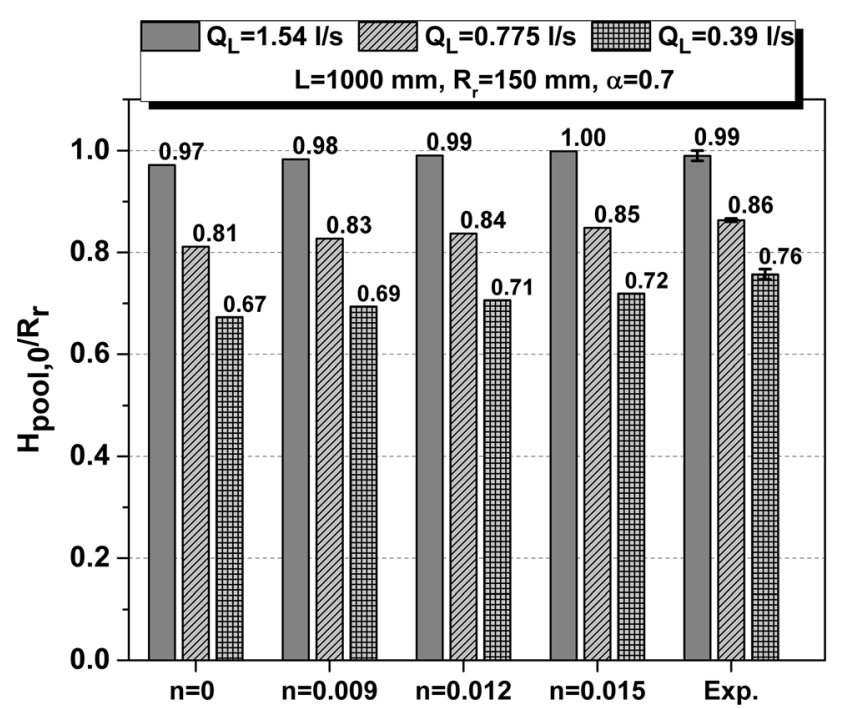

Fig. 7-Variation of the computed $H_{\text {pool, }, 0}$ with changing $\mathrm{n}$ values, and its comparison with experimental results.

computed profiles show an acceptable agreement with the experimental results. The relative error of the computed results is between about 0 and $11 \%$ at $y=0$. It can be concluded that the hydraulic theory can predict water profiles in the nip of continuous casting rolls to a good approximation.

\section{Use of Alternative Criteria as Boundary Condition at the End of the Channel}

As described, the hydraulic model with boundary condition for $H_{\text {pool, } \mathrm{L}}$ derived from the $F r=1$ criterion gives good agreement with the experimental data. It is to be noted that these computational results present so-to-speak first principle results. The differential Eq. [1] for open channel flow was solved with the criterion $\mathrm{Fr}=1$ which is the natural criterion for free overfall. No other foreign datum was introduced. Therefore, the agreement between computed and measured $H_{\text {pool }}$ profiles is proof of the correctness of the model. Nevertheless, on closer inspection of the profiles in Figure 8 it becomes evident that at the channel end $y$ $=L$ the computed pool height is higher than the experimental height in most experiments. That is, there seems to be a systematic deviation with the computed height being higher than the experimental one. This means that the Froude criterion $\mathrm{Fr}=1$ is not always fulfilled exactly. Consequently, other criteria might be looked at to see whether they possibly give still better agreement with the experimental height profiles particularly at the end of the channel.

In a review ${ }^{[17]}$ on free overfall in open channels, various channel geometries were considered: rectangular, trapezoidal, circular, parabolic, triangular channels. The treatment by Rouse of the rectangular channel was the starting point for the subsequent studies of other channels. The applicability of the Rouse concept to the present problem of the continuous casting has been investigated. The results are as follows: 


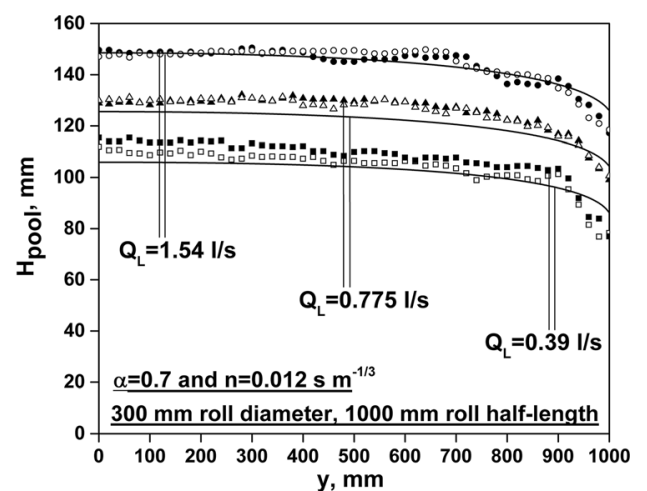

(a)

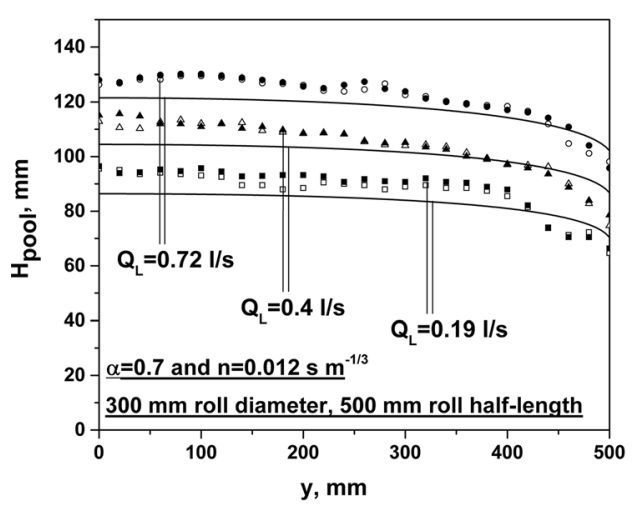

(b)

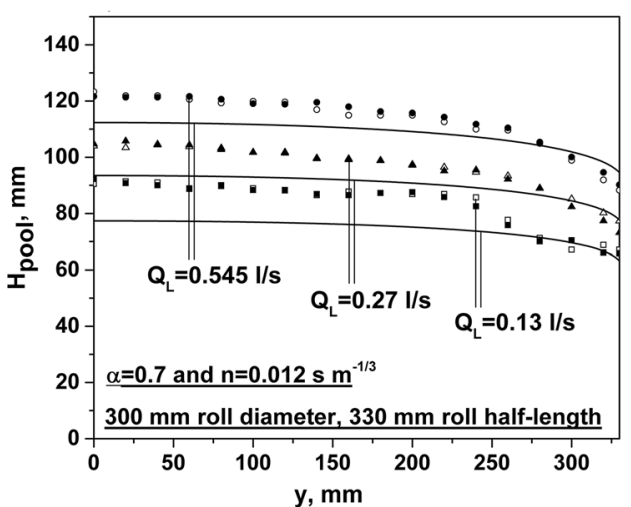

(c)

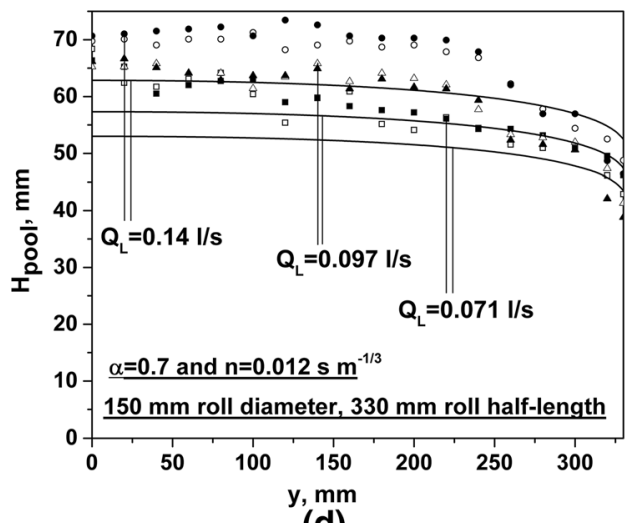

(d)
Fig. 8-Comparison for selected experiments between measured (symbols) and computed (solid lines) pool height profiles. The two symbols, one open and one filled in the diagrams refer to two different experiments with slightly different $Q_{\mathrm{L}}, e . g$. in $(d)$ the two experiments denoted with $Q_{\mathrm{L}}=0.14 \mathrm{~L} \mathrm{~s}^{-1}$ are for $Q_{\mathrm{L}}=0.13$ and $0.15 \mathrm{~L} \mathrm{~s}^{-1}$. Data for $(a) Q_{\mathrm{L}}=1.54,0.77,0.39 \mathrm{~L} \mathrm{~s}^{-1},(b) Q_{\mathrm{L}}=0.72$, $0.40,0.19 \mathrm{~L} \mathrm{~s}^{-1},(c) Q_{\mathrm{L}}=0.545,0.27,0.13 \mathrm{~L} \mathrm{~s}^{-1}$, and (d) $Q_{\mathrm{L}}=$ $0.14,0.097,0.071 \mathrm{~L} \mathrm{~s}^{-1}$.

1. Use of Rouse criterion as boundary condition at the end of the channel

The equation for the discharge $Q_{\mathrm{L}}$ at the end of the channel is given by Rouse $\left[{ }^{18]}\right.$ as

$$
Q_{\mathrm{L}}=1.654 \sqrt{g} T H_{\text {pool }, \mathrm{L}}^{3 / 2},
$$

where $T$ is the width of the rectangular channel. Using

$$
T H_{\text {pool, } \mathrm{L}}=A_{\mathrm{L}}
$$

Equation [21] can be written as

$$
Q_{\mathrm{L}}=1.654 \sqrt{g} A_{\mathrm{L}}^{3 / 2} T^{-1 / 2}
$$

Equation [23] is generalized for application to the geometry of the continuous casting nip by expressing $T$ according to

$$
T=\frac{\mathrm{d} A}{\mathrm{~d} H_{\text {pool }}}
$$

yielding

$$
Q_{\mathrm{L}}=1.654 \sqrt{g}\left(A^{3} \frac{\mathrm{d} H_{\text {pool }}}{\mathrm{d} A}\right)_{\mathrm{y}=\mathrm{L}}^{1 / 2}
$$

Inserting Eq. [25] into [14] gives

$$
\left(\frac{\mathrm{d} H_{\text {pool }}}{\mathrm{d} y}\right)_{y=L}=\frac{-S_{\mathrm{f}}-\frac{2 \alpha Q_{\mathrm{L}}{ }^{2}}{L g A_{\mathrm{L}}{ }^{2}}}{1-\frac{\alpha Q_{\mathrm{L}}{ }^{2}}{g}\left(\frac{\mathrm{d} A}{A^{3} \mathrm{~d} H_{\text {pool }}}\right)_{\mathrm{y}=\mathrm{L}}}=\frac{-S_{\mathrm{f}}-\frac{2 \alpha Q_{\mathrm{L}}{ }^{2}}{L g A_{\mathrm{L}}{ }^{2}}}{1-1.654^{2} \alpha}
$$

Since the denominator of Eq. [26] must be positive, it follows

$$
1-1.654^{2} \alpha>0 \text { or } 1.654^{2} \alpha<1 \text { or } \alpha<\frac{1}{1.654^{2}}=0.3655
$$

So, the value of $\alpha$ must be chosen smaller than 0.3655 . The diagram in Figure 9 was computed with $\alpha=0.365$.

2. Use of empirical criterion as boundary condition at the end of the channel

It was shown in Figure 5 of the previous paper ${ }^{[5]}$ that the empirical Eq. (2) of Reference 5 for $H_{\text {pool,L }} / R_{\mathrm{r}}$ agrees better with the experimental data than the Froude equation. Hence, the applicability of this equation as boundary condition was explored. Equation [2] of the precious paper ${ }^{[5]}$ is given as 


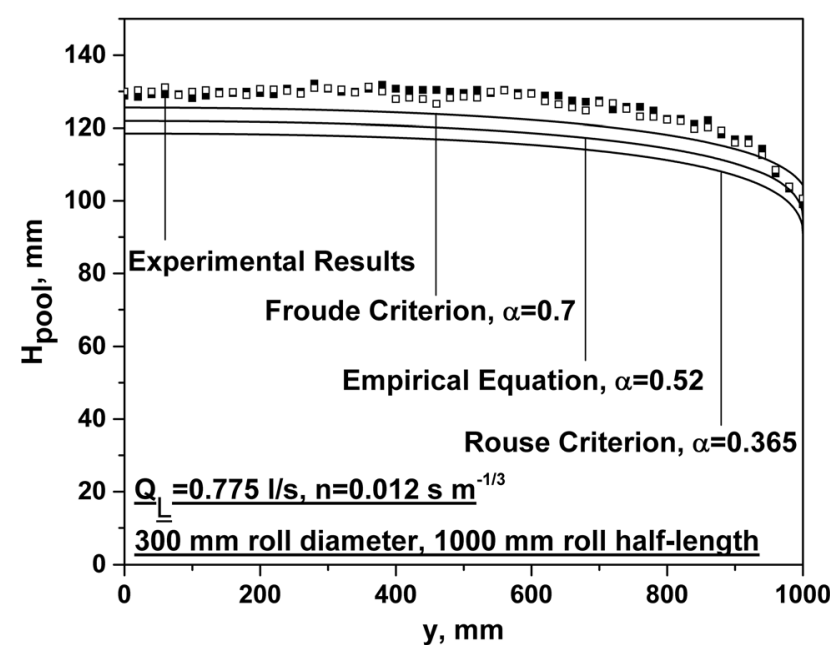

Fig. 9-Comparison between profiles obtained with three different boundary condition and experimental data.

$$
\frac{H_{\text {pool }, \mathrm{L}}}{R_{\mathrm{r}}}=1.10-0.150 \log \left(\frac{g R_{\mathrm{r}}^{5}}{Q_{\mathrm{L}}^{2}}\right)
$$

The quantity $\left(\frac{R_{\mathrm{r}}^{5} \mathrm{~d} A}{A^{3} \mathrm{~d} H_{\mathrm{pool}}}\right)_{y=L}$ is computed from Eq. [7] and the discharge rate $Q_{\mathrm{L}}$ is obtained from [28], and both are inserted into [14]. Since the denominator of [14] must be positive, it follows

$$
\begin{aligned}
1 & -\frac{\alpha Q_{\mathrm{L}}^{2}}{g R_{\mathrm{r}}^{5}}\left(\frac{R_{\mathrm{r}}^{5} \mathrm{~d} A}{A^{3} \mathrm{~d} H_{\text {pool }}}\right)_{y=L}>0 \text { or } \alpha<\frac{g R_{\mathrm{r}}^{5}}{Q_{\mathrm{L}}^{2}} \\
& \times\left(\frac{1}{\left(\frac{R_{\mathrm{r}}^{5} \mathrm{~d} A}{A^{3} \mathrm{~d} H_{\text {pool }}}\right)_{y=L}}\right)
\end{aligned}
$$

In this case, $\alpha$ depends on $Q_{\mathrm{L}}$. For instance, $Q_{\mathrm{L}}=0.775 \mathrm{~L} \mathrm{~s}^{-1}=0.000775 \mathrm{~m}^{3} \mathrm{~s}^{-1}$ and $R_{\mathrm{r}}=150$ $\mathrm{mm}$ yields

$$
\frac{H_{\text {pool }, \mathrm{L}}}{R_{\mathrm{r}}}=0.63599 \text { and }\left(\frac{R_{\mathrm{r}}^{5} \mathrm{~d} A}{A^{3} \mathrm{~d} H_{\text {pool }}}\right)_{y=L}=2353.26[30]
$$

Hence,

$$
\alpha<\frac{1239.868939}{2353.26}=0.5269
$$

The curve in Figure 9 was computed with $\alpha=0.52$.

Figure 9 presents the comparison between the profiles obtained with Froude criterion, Rouse criterion, Empirical criterion and the experimental data. It is evident that the Froude profile is still representing the experimental points best. The comparison was carried out for several other conditions yielding the same conclusion.

\section{CONCLUSION}

Open channel hydraulics has been applied for computation of the water pool height in the nip between roll and strand in continuous slab casting. The differential equation describing the change of pool height for the spatially varied flow with increasing discharge was solved with the Runge-Kutta technique using as boundary condition the pool height at the end of the nip. The friction slope in the differential equation was taken to be according to the Manning formula. The effects of the Manning factor $\mathrm{n}$ and the energy coefficient $\alpha$ were determined in sets of computation.

The pool height at the end of the channel (nip) was derived from the Froude criterion for free overfall. Alternatively, the Rouse criterion and the empirical equation obtained in our previous investigation were applied which, however, produced pool height profiles agreeing less well with the experimental profiles than the Froude profiles.

The present work gives a quantitative understanding of the water height profile in the nip between roll and strand in continuous slab casting. It is believed that the results will be helpful for the design of the cooling system in the zone of slab casters and for the operation of the caster.

\section{CONFLICT OF INTEREST}

On behalf of all authors, the corresponding author states that there is no conflict of interest.

\section{FUNDING}

Open Access funding enabled and organized by Projekt DEAL.

\section{OPEN ACCESS}

This article is licensed under a Creative Commons Attribution 4.0 International License, which permits use, sharing, adaptation, distribution and reproduction in any medium or format, as long as you give appropriate credit to the original author(s) and the source, provide a link to the Creative Commons licence, and indicate if changes were made. The images or other third party material in this article are included in the article's Creative Commons licence, unless indicated otherwise in a credit line to the material. If material is not included in the article's Creative Commons licence and your intended use is not permitted by statutory regulation or exceeds the permitted use, you will need to obtain permission directly from the copyright holder. To view a copy of this licence, visit http://creativec ommons.org/licenses/by/4.0/. 


\section{NOMENCLATURE}

$g$

$R_{\mathrm{r}}$

$T$

A

$P_{\mathrm{W}}$

$R_{\mathrm{h}}$

$D_{\text {depth }}$

Fr

$H_{\text {pool }}$

$H_{\text {pool, } 0}$

$H_{\text {pool,L }}$

$L$

$Y$

$q$

$Q$

$Q_{\mathrm{L}}$

$S_{\mathrm{f}}$

$\alpha$

$n$

Wetted perimeter (m)

Hydraulic radius (m)

Hydraulic depth (m)

Froude number (-)

Pool height ( $\mathrm{m}, \mathrm{mm})$ $\mathrm{mm}$ ) $\mathrm{s}^{-1}$ ) $\left(\mathrm{m}^{3} \mathrm{~s}^{-1}, \mathrm{~L} \mathrm{~s}^{-1}\right)$

Friction slope (-)

Energy coefficient (-)
Spatial coordinate along roll (tube) (m, mm) Gravity constant $\left(9.8067 \mathrm{~m} \mathrm{~s}^{-2}\right)$

Radius of roll (tube) (m, mm)

Width of the flow surface $(\mathrm{m})$

Cross-sectional area of pool $\left(\mathrm{m}^{2}\right)$

Pool height at $y=0(\mathrm{~m}, \mathrm{~mm})$

Pool height at $y=L(\mathrm{~m}, \mathrm{~mm})$

Length of pool in model experiment, roll

half-length in caster $(\mathrm{m}, \mathrm{mm})$

Spatial coordinate along roll (tube) $L-y(\mathrm{~m}$,

Change of discharge along the nip $\left(\mathrm{m}^{2} \mathrm{~s}^{-1}\right)$

Volumetric flow rate (discharge) $\left(\mathrm{m}^{3} \mathrm{~s}^{-1}, \mathrm{~L}\right.$

$Q_{\mathrm{L}} \quad$ Volumetric flow rate at $y=L$ (discharge)

Manning friction coefficient $\left(\mathrm{s} \mathrm{m}^{-1 / 3}\right)$

\section{REFERENCES}

1. S.G. Hibbins and J.K. Brimacombe: in Continuous Casting, vol. 2, ISS-AIME, 1984, pp. 139-51.

2. K Stephan: Wärme- und Stoffübertragung, Springer, Berlin, 1988, pp. 137-64.

3. W. Beitz and K.-H. Küttner (eds.): DUBBEL - Taschenbuch Für Den Maschinenbau, 18th ed. Springer, Berlin, 1995.
4. H. Litterscheidt, B. Hesse, and F.J. Schetter: in The Sixth Japan-Germany Seminar, Tokyo, 1984, pp. 173-86.

5. S. Khani, H. Palkowski, and K. Schwerdtfeger: Ironmak. Steelmak., 2020, vol. 47 (8), pp. 942-47.

6. N. Yamasaki, S. Shima, K. Tsunenari, S. Hayashi, and M. Doki: ISIJ Int., 2015, vol. 55 (5), pp. 976-83.

7. E.A. Mizikar: Iron Steel Eng., 1970, vol. 47, pp. 53-60.

8. R. Jeschar, E. Specht, and C. Köhler: in Theory and Technology of Quenching, B. Liščić, H. Tensi, and W. Luty, eds., Springer, Berlin, 1992, pp. 73-92.

9. U. Reiner: Wärmeübertragung durch Spritzwasserkühlung heißer Oberflächen im Bereich der stabilen Filmverdampfung, Dissertation, Technical University of Clausthal, 1987.

10. K. Schwerdtfeger: Rechnerisches Modellieren von Vorgängen beim Stranggießen von Stahl, in Erstarrung metallischer Schmelzen, P.R. Sahm, ed., DGM-Informationsgesellschaft Verlag, 1988, pp. 205-24.

11. K. Schwerdtfeger: Solidification rate in casting processes, in $\mathrm{Ad}$ vanced Physical Chemistry for Process Metallurgy, N. Sano, W.-K. Lu, and P. Riboud, eds., Academic Press, 1997, pp. 381-419.

12. K. Schwerdtfeger: Heat withdrawal in continuous casting of steel, in The Making, Shaping, and Treating of Steel, 11th ed., AISI Steel Foundation, Pittsburgh, 2003, pp. 1-41.

13. B. Barber, B. Patrick, H. Sha, K.H. Spitzer, R. York, R. Scholz, R. Jeschar, and H. Kraushaar: Determination of Strand Surface Temperatures in Continuous Casting, European Commission, Contract No. 7210-CA/164/832 Final Report EUR 18370 EN, 1998.

14. T. Nozaki, J.-I. Matsuno, K. Murata, H. Ooi, and K. Kodama: Trans. ISIJ, 1978, vol. 18, pp. 330-38.

15. V. Te Chow: Open-Channel Hydraulics, McGraw-Hill, New York, 1959.

16. Engineering ToolBox: https://www.engineeringtoolbox.com/man nings-roughness-d_799.html (accessed 13 August 2020).

17. S. Dey: Flow Meas. Instrum., 2002, vol. 13, pp. 247-64.

18. H. Rouse: Am. Soc. Civ. Eng., 1936, vol. 6, pp. 257-60.

Publisher's Note Springer Nature remains neutral with regard to jurisdictional claims in published maps and institutional affiliations. 